\title{
ANALISIS KINERJA COOLANT PADA RADIATOR
}

\author{
Alexander Clifford, Abrar Riza dan Steven Darmawan \\ Program Studi Teknik Mesin, Fakultas Teknik Universitas Tarumanagara \\ e-mail: Alexander.clifford@hotmail.co.id
}

\begin{abstract}
This research learn about characteristic of radiator coolant effectiveness, which are influenced by flow rate, density, and fluid viscosity. Experimental method is used to get parameters: such as coolant temperature, air temperature and flow rate. This study use $\varepsilon$-NTU method to analyze the data. The results of coolant $A, B$, and water have effectiveness of $40 \%, 37 \%$, and $36 \%$ respectively, it is caused by coolant A have the biggest Universal coefficient number and convection coefficient number are compared with coolant B and water.
\end{abstract}

Keywords: Radiator, effectiveness, radiator coolant, $\varepsilon-N T U$ method.

\section{PENDAHULUAN}

Heat exchanger atau penukar kalor merupakan alat yang digunakan untuk menukar kalor. Alat penukar kalor ini berfungsi untuk mendinginkan maupun memanaskan suatu komponen, tergantung dari tujuan pemasangan alat penukar kalor tersebut. Tujuan-tujuan dari penggunaan alat penukar kalor adalah untuk mengoptimalkan kinerja dari mesin, mendinginkan atau memanaskan suatu fluida dengan melakukan perpindahan panas secara konveksi dan konduksi.

Salah satu jenis alat penukar kalor yang sering digunakan sehari hari adalah radiator. Radiator dipakai di semua mobil dan di beberapa jenis motor. Pada awalnya motor tidak menggunakan radiator, hanya menggunakan pendingin udara dengan sirip, namun seiring dengan berkembangnya teknologi, radiator dipakai pada motor. Radiator digunakan untuk menjaga suhu mesin agar tidak overheating saat dioperasikan. Mesin tidak dapat mengkonversi energi panas dari bahan bakar 100 persen menjadi tenaga, ada energi panas yang hilang menjadi gas buang dan energi panas tersebut diserap oleh mesin itu sendiri [1].

Sistem pendinginan radiator menggunakan media fluida cair yang sering disebut sebagai coolant. Sistem pendinginan menggunakan fluida cair lebih rumit dan lebih mahal, namun memiliki optimalitas yang tinggi. Coolant dipasaran terdapat berbagai jenis dengan harga yang beragam. Beberapa merk coolant mengklaim dapat menjadi media pemindah panas terbaik untuk radiator.

Dalam penelitian Analisis Kinerja Coolant pada radiator ini terdapat beberapa masalah yang ada, yaitu Apakah coolant A memiliki perpindahan panas yang lebih baik daripada coolant B, Bagaimanakah jika dibandingkan dengan air dan Bagaimanakah efek laju massa fluida untuk mendapatkan karakteristik perpindahan panas pada radiator.

Batasan masalah pada penelitian ini adalah Fluida yang digunakan berbasis cairan, yaitu air dengan konduktivitas $0,6 \mathrm{~W} / \mathrm{m} . \mathrm{K}$, coolant $A$ dengan konduktivitas $0,72 \mathrm{~W} / \mathrm{m} . \mathrm{K}$ dan coolant $B$ dengan konduktivitas $0,65 \mathrm{~W} / \mathrm{m} . \mathrm{K}$, pengaturan laju massa fluida menggunakan katup, radiator yang dipakai berupa radiator flat fin type, panas disimulasi dengan menggunakan heater yang dapat mewakili panas engine motor bakar.

Penelitian ini bertujuan untuk mendapatkan karakteristik beberapa jenis coolant sebagai fluida pendingin radiator dan mengetahui kinerja coolant tersebut jika dibandingkan dengan air.

\section{METODE PENELITIAN}

Metode yang digunakan dalam penelitian ini adalah studi literatur dan uji ekperimental dengan menggunakan rangkaian alat simulasi radiator, berpemanas elektrik untuk mewakili panas engine motor bakar dengan diagram alir penelitian tampak pada Gambar 1.

Metode pengolahan data yang digunakan pada penelitian ini adalah metode $\varepsilon$-NTU. Penelitian ini menggunakan metode $\varepsilon$-NTU karena metode ini dapat menganalisis efektivitas suatu alat penukar kalor. 


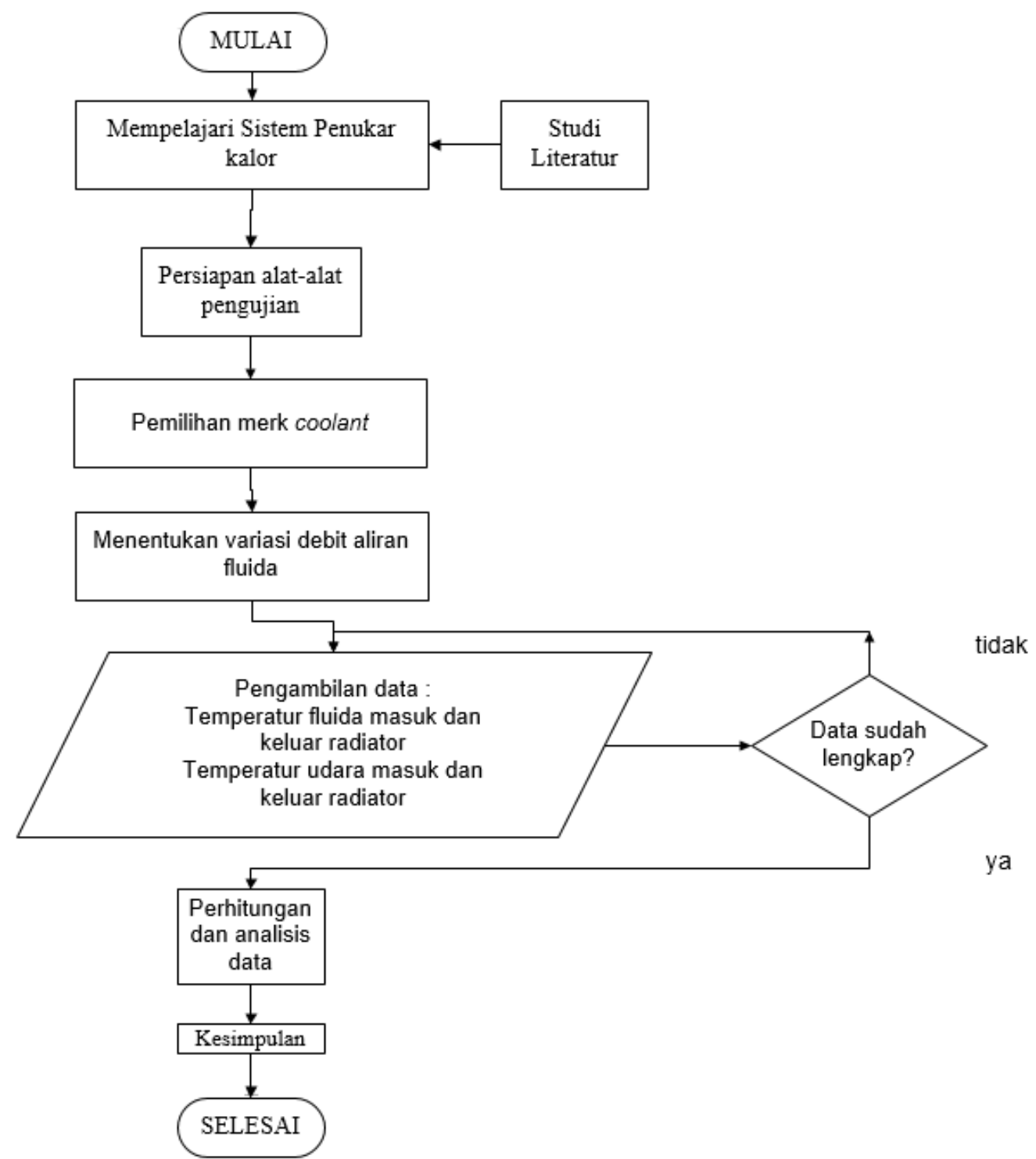

Gambar 1. Diagram alir penelitian

\section{HASIL DAN PEMBAHASAN}

Setelah dilakukan uji eksperimental dan pengolahan data, maka hasil dari penelitian ini adalah sebagai berikut:

Tabel 1. Data hasil pengolahan air

\begin{tabular}{cccccc}
\hline Bukaan Katup & 1 & 2 & 3 & 4 & 5 \\
\hline $\mathrm{Q}_{\mathrm{h}}(\mathrm{ml} / \mathrm{s})$ & 60 & 102 & 160 & 201 & 240.5 \\
$\mathrm{~T}_{\text {h.in }}$ & $100^{\circ} \mathrm{C}$ & $100^{\circ} \mathrm{C}$ & $100^{\circ} \mathrm{C}$ & $100^{\circ} \mathrm{C}$ & $100^{\circ} \mathrm{C}$ \\
$\mathrm{T}_{\text {h.out }}$ & $85.2 \mathrm{C}$ & $84^{\circ} \mathrm{C}$ & $81,1^{\circ} \mathrm{C}$ & $76,4^{\circ} \mathrm{C}$ & $74^{\circ} \mathrm{C}$ \\
$\mathrm{T}_{\text {c.in }}$ & $28,9^{\circ} \mathrm{C}$ & $28,1^{\circ} \mathrm{C}$ & $27,9^{\circ} \mathrm{C}$ & $27,9^{\circ} \mathrm{C}$ & $28,4^{\circ} \mathrm{C}$ \\
$\mathrm{T}_{\text {c.out }}$ & $30,2^{\circ} \mathrm{C}$ & $29,7^{\circ} \mathrm{C}$ & $29,5^{\circ} \mathrm{C}$ & $30,8^{\circ} \mathrm{C}$ & $38,8^{\circ} \mathrm{C}$ \\
$\mathrm{V}_{\mathrm{c}}$ & $0,8 \mathrm{~m} / \mathrm{s}$ & $0,8 \mathrm{~m} / \mathrm{s}$ & $0,8 \mathrm{~m} / \mathrm{s}$ & $0,8 \mathrm{~m} / \mathrm{s}$ & $0,8 \mathrm{~m} / \mathrm{s}$ \\
$\mathrm{Q}_{\text {act }}(\mathrm{W})$ & 62,456 & 76,8 & 76,734 & 139,2 & 115,18 \\
$\varepsilon(\%)$ & 20,81 & 22,26 & 25,6 & 33,28 & 36,3 \\
$\mathrm{U}_{\mathrm{h}}\left(\mathrm{W} / \mathrm{m}^{2} \mathrm{~K}\right)$ & 7,03 & 8,533 & 6,315 & 12,889 & 10,337 \\
Reynolds number & 16976 & 28860 & 45270 & 56871 & 67906 \\
$\mathrm{H}\left(\mathrm{W} / \mathrm{m}^{2} \mathrm{~K}\right)$ & 202,74 & 309,96 & 392,1 & 470,6 & 542,3 \\
\hline
\end{tabular}


Tabel 2. Data hasil pengolahan coolant A

\begin{tabular}{cccccc}
\hline Bukaan Katup & 1 & 2 & 3 & 4 & 5 \\
\hline $\mathrm{Q}_{\mathrm{h}}(\mathrm{ml} / \mathrm{s})$ & 60 & 102 & 160 & 201 & 240.5 \\
$\mathrm{~T}_{\text {h.in }}$ & $100^{\circ} \mathrm{C}$ & $100^{\circ} \mathrm{C}$ & $100^{\circ} \mathrm{C}$ & $100^{\circ} \mathrm{C}$ & $100^{\circ} \mathrm{C}$ \\
$\mathrm{T}_{\text {h.out }}$ & $87^{\circ} \mathrm{C}$ & $82^{\circ} \mathrm{C}$ & $78.2^{\circ} \mathrm{C}$ & $74,8^{\circ} \mathrm{C}$ & $69^{\circ} \mathrm{C}$ \\
$\mathrm{T}_{\text {c.in }}$ & $23,6^{\circ} \mathrm{C}$ & $23,7^{\circ} \mathrm{C}$ & $23,7^{\circ} \mathrm{C}$ & $23,7^{\circ} \mathrm{C}$ & $23,7^{\circ} \mathrm{C}$ \\
$\mathrm{T}_{\text {c.out }}$ & $28,3^{\circ} \mathrm{C}$ & $28,9^{\circ} \mathrm{C}$ & $30,1^{\circ} \mathrm{C}$ & $30,6^{\circ} \mathrm{C}$ & $31,4^{\circ} \mathrm{C}$ \\
$\mathrm{V}_{\mathrm{c}}$ & $0,8 \mathrm{~m} / \mathrm{s}$ & $0,8 \mathrm{~m} / \mathrm{s}$ & $0,8 \mathrm{~m} / \mathrm{s}$ & $0,8 \mathrm{~m} / \mathrm{s}$ & $0,8 \mathrm{~m} / \mathrm{s}$ \\
$\mathrm{Q}_{\text {act }}(\mathrm{W})$ & 225,55 & 249,5 & 307,16 & 331,2 & 369,5 \\
$\varepsilon(\%)$ & 17 & 23,58 & 28,6 & 30,4 & 40,6 \\
$\mathrm{U}_{\mathrm{h}}\left(\mathrm{W} / \mathrm{m}^{2} \mathrm{~K}\right)$ & 25,06 & 24,64 & 31,311 & 37,27 & 33,107 \\
Reynolds number & 13623 & 23160 & 36329 & 45639 & 54494 \\
$\mathrm{H}\left(\mathrm{W} / \mathrm{m}^{2} \mathrm{~K}\right)$ & 288,26 & 440,71 & 631,77 & 758,28 & 873,85 \\
\hline
\end{tabular}

Tabel 3. Data hasil pengolahan coolant B

\begin{tabular}{cccccc}
\hline Bukaan Katup & 1 & 2 & 3 & 4 & 5 \\
\hline $\mathrm{Q}_{\mathrm{h}}(\mathrm{ml} / \mathrm{s})$ & 60 & 102 & 160 & 201 & 240.5 \\
$\mathrm{~T}_{\text {h.in }}$ & $100^{\circ} \mathrm{C}$ & $100^{\circ} \mathrm{C}$ & $100^{\circ} \mathrm{C}$ & $100^{\circ} \mathrm{C}$ & $100^{\circ} \mathrm{C}$ \\
$\mathrm{T}_{\text {h.out }}$ & $88,4^{\circ} \mathrm{C}$ & $83^{\circ} \mathrm{C}$ & $81,6^{\circ} \mathrm{C}$ & $77^{\circ} \mathrm{C}$ & $72^{\circ} \mathrm{C}$ \\
$\mathrm{T}_{\text {c.in }}$ & $24,4^{\circ} \mathrm{C}$ & $24,4^{\circ} \mathrm{C}$ & $24,4^{\circ} \mathrm{C}$ & $24,4^{\circ} \mathrm{C}$ & $24,4^{\circ} \mathrm{C}$ \\
$\mathrm{T}_{\text {c.out }}$ & $27,4^{\circ} \mathrm{C}$ & $27,4^{\circ} \mathrm{C}$ & $28,2^{\circ} \mathrm{C}$ & $28,6^{\circ} \mathrm{C}$ & $29,2^{\circ} \mathrm{C}$ \\
$\mathrm{V}_{\mathrm{c}}$ & $0,8 \mathrm{~m} / \mathrm{s}$ & $0,8 \mathrm{~m} / \mathrm{s}$ & $0,8 \mathrm{~m} / \mathrm{s}$ & $0,8 \mathrm{~m} / \mathrm{s}$ & $0,8 \mathrm{~m} / \mathrm{s}$ \\
$\mathrm{Q}_{\text {act }}(\mathrm{W})$ & 144 & 144,5 & 192 & 202,4 & 230,44 \\
$\varepsilon(\%)$ & 15,3 & 23 & 24,3 & 30,4 & 37 \\
$\mathrm{U}_{\mathrm{h}}\left(\mathrm{W} / \mathrm{m}^{2} \mathrm{~K}\right)$ & 13,789 & 12,75 & 16,27 & 16,133 & 21,489 \\
Reynolds number & 16083 & 27341 & 42888 & 53878 & 64332 \\
$\mathrm{H}\left(\mathrm{W} / \mathrm{m}^{2} \mathrm{~K}\right)$ & 276,65 & 422,95 & 606,72 & 727,72 & 838,65 \\
\hline
\end{tabular}

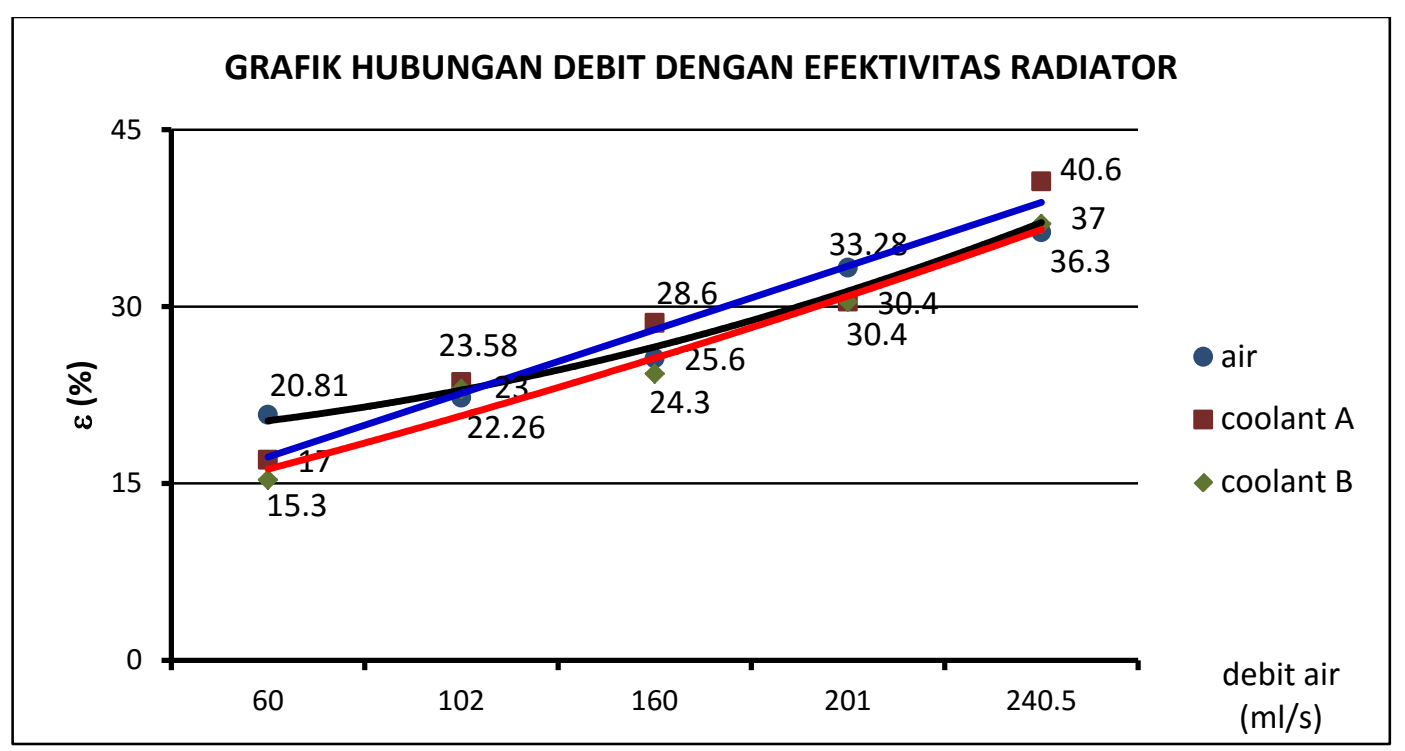

Gambar 2. Grafik hubungan debit dengan efektivitas radiator

Berdasarkan data hasil pengujian, diperoleh nilai efektivitas terbesar coolant $A$ sebesar $40.6 \%$, efektivitas terbesar coolant $B$ sebesar $37 \%$, dan efektivitas terbesar air $36.3 \%$ pada debit aliran fluida sebesar $240.5 \mathrm{ml} / \mathrm{s}$. Coolant A memiliki efektivitas terbesar karena konduktivitas coolant $A$ bernilai terbesar jika dibandingkan dengan coolant $B$ dan air, sehingga koefisien perpindahan panas sistem coolant A memiliki nilai yang terbesar, yang berdampak pada efektivitas dari radiator yang 
dihasilkan terbesar. Berdasarkan Gambar 2, dapat diketahui bahwa debit atau laju aliran massa fluida dapat mempengaruhi hasil efektivitas dari radiator. Hal ini dapat terjadi karena besar debit berbanding lurus dengan besar Reynolds Number, dimana semakin besar Reynolds Number, fluida memiliki kecenderungan bersifat turbulen, ketika fluida memiliki kecenderungan bersifat turbulen, semakin baik fluida tersebut akan melepaskan panas. Dari ketiga jenis fluida cair yang digunakan untuk pengujian ekperimental, terlihat bahwa semakin besar debit aliran air, semakin besar juga efektivitas dari radiator.

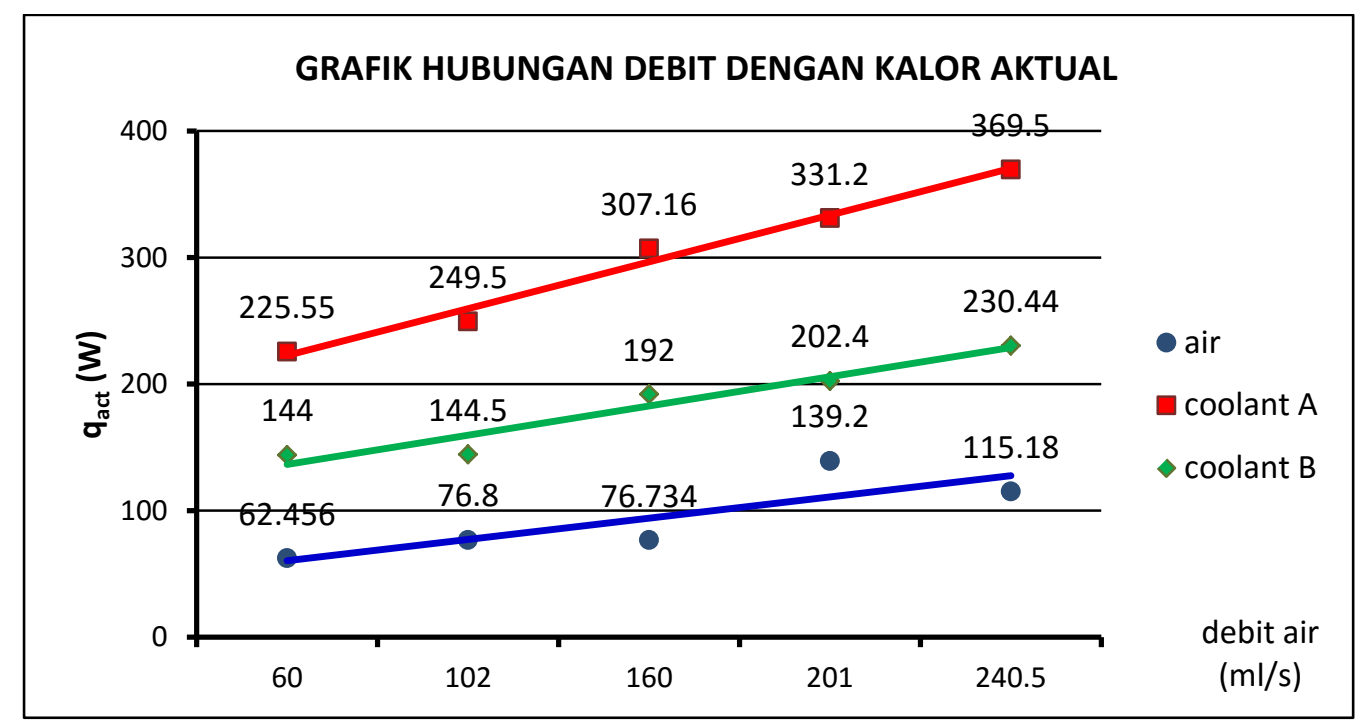

Gambar 3. Grafik hubungan debit dengan kalor aktual.

Pada penelitian ini, diperoleh kalor aktual yang dapat dilepas coolant sebesar $369.5 \mathrm{~W}$ oleh coolant $A$. Hal ini dapat terjadi karena coolant $A$ memiliki konduktivitas termal terbesar, jika dibandingkan dengan air dan coolant $B$ sebesar 0,72 W/m.K. Berdasarkan Gambar 3, dapat diketahui bahwa besar kalor yang dapat dipindahkan oleh fluida cair pada pengujian eksperimental ini dipengaruhi oleh debit aliran fluida. Semakin besar debit aliran fluida, semakin besar juga kalor aktual yang dapat dilepas oleh fluida tersebut. Hal ini dapat terjadi karena besar debit berbanding lurus dengan besar Reynolds Number, dimana semakin besar Reynolds Number, fluida memiliki kecenderungan bersifat turbulen, ketika fluida memiliki kecenderungan bersifat turbulen, semakin baik fluida tersebut akan melepaskan panas. Dengan demikian hal ini menandakan bahwa debit aliran air harus diatur besar agar fluida sebagai media pendingin dapat melepas panasnya dengan baik.

Pada penelitian ini, diperoleh hasil koefisien perpindahan panas sistem $\left(\mathrm{U}_{\mathrm{h}}\right)$ sebesar 37.3 $\mathrm{W} / \mathrm{m}^{2} \mathrm{~K}$ pada saat debit aliran massa $201 \mathrm{ml} / \mathrm{s}$ oleh coolant $A$. Coolant B mendapatkan peringkat ke 2 dalam besarnya nilai koefisien perpindahan sistem yang dihasilkan, dan air mendapatkan peringkat terakhir. Hal ini terjadi karena coolant A memiliki konduktivitas termal terbesar sehingga koefisien perpindahan sistem yang dihasilkan paling besar jika dibandingkan dengan coolant $B$ dan air. Berdasarkan Gambar 4, dapat diketahui bahwa debit aliran fluida mempengaruhi koefisien perpindahan sistem. Koefisien perpindahan panas sistem memiliki kecenderungan membesar seiring dengan membesarnya debit aliran fluida. Hasil penelitian dari Ribut Supriyanto dkk. (2013) juga menyatakan bahwa koefisien perpindahan panas sistem akan meningkat seiring dengan laju aliran massa fluida. 


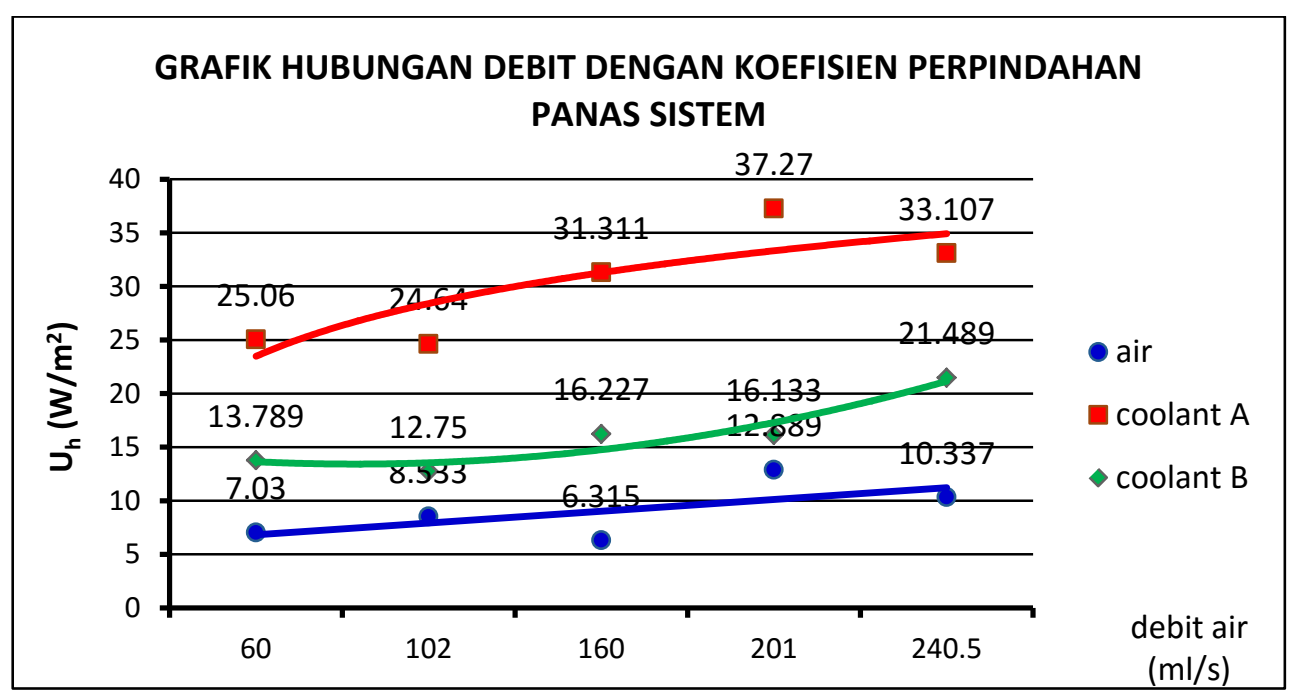

Gambar 4. Grafik hubungan debit dengan koefisien perpindahan panas sistem

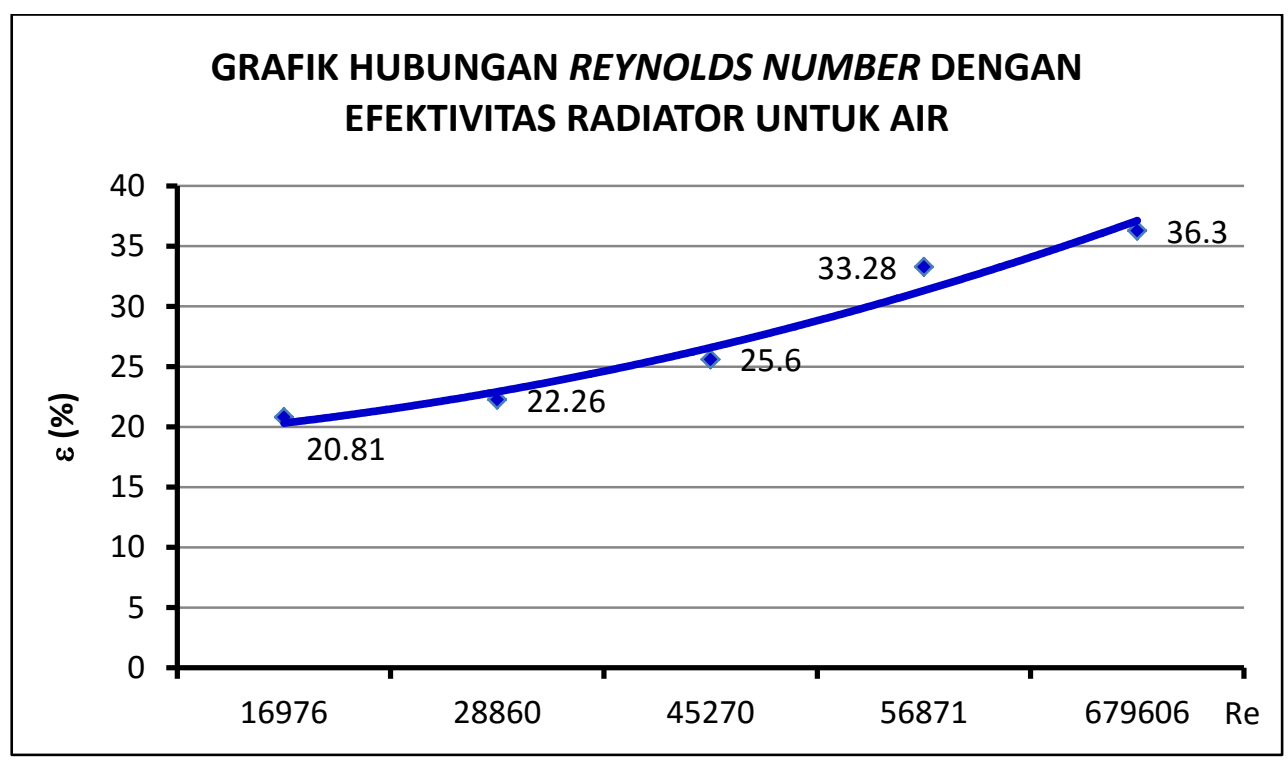

Gambar 5. Grafik hubungan Reynolds Number dengan efektivitas radiator pada fluida air.

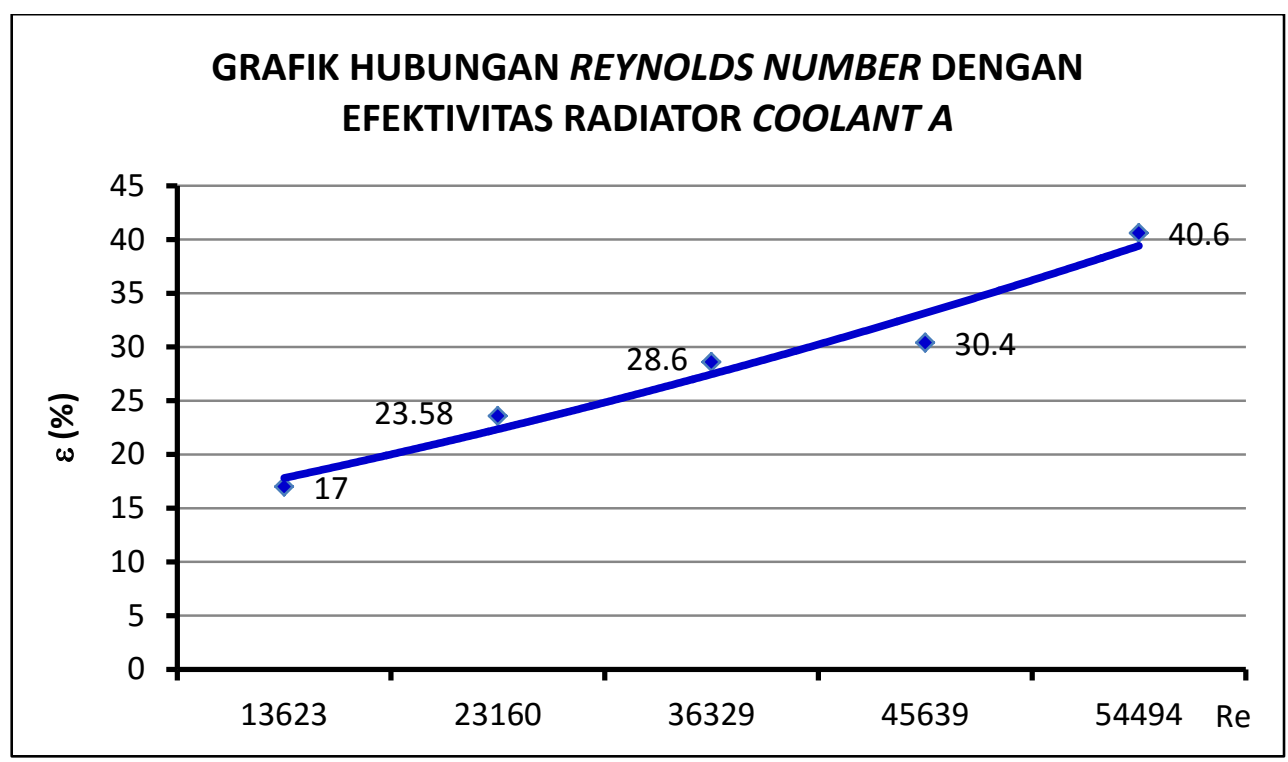

Gambar 6. Grafik hubungan Reynolds Number dengan efektivitas radiator pada coolant A. 


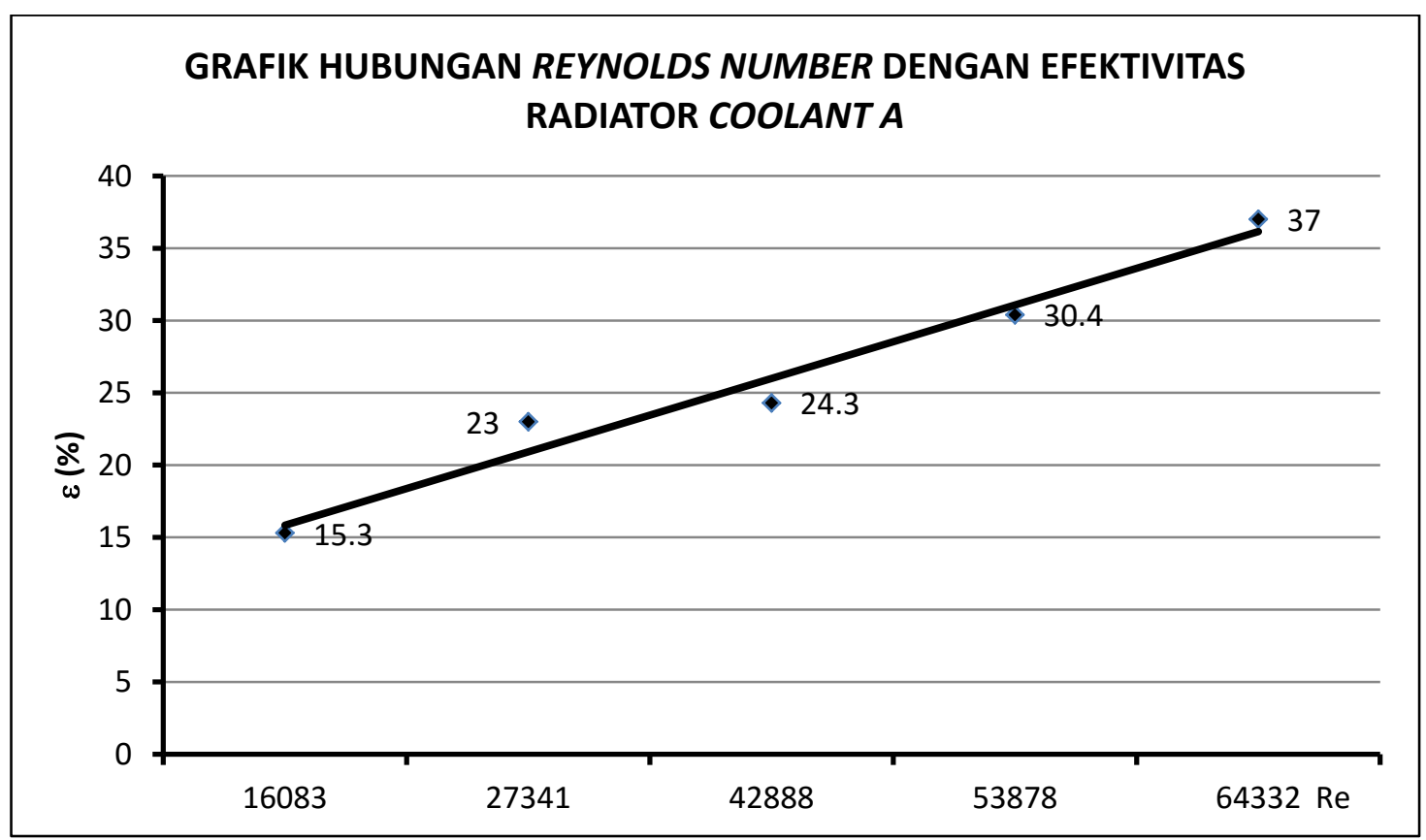

Gambar 7. Grafik hubungan Reynolds Number dengan efektivitas radiator pada coolant B.

Berdasarkan penelitian yang telah dilakukan, diperoleh hasil bahwa semakin besar nilai viskositas, semakin kecil nilai Reynolds Number yang dihasilkan oleh fluida. Hal ini terjadi karena besarnya Reynolds Number berbanding terbalik dengan nilai viskositas. Hal ini dibuktikan pada hasil penelitian, nilai Reynolds Number yang dimiliki air paling besar jika dibandingkan dengan coolant $A$ dan coolant $B$, dimana viskositas air sebesar $3 \times 10^{-4}$ Pa.s, viskositas coolant $A$ sebesar $4 \times 10^{-4}$ Pa.s, dan viskositas coolant $B$ sebesar $3,23 \times 10^{-4}$ Pa.s.

Pada hasil penelitian yang nampak pada Gambar 5, Gambar 6, dan Gambar 7, dapat diketahui bahwa efektivitas untuk setiap fluida kerja akan memiliki kecenderungan membesar seiring dengan besarnya Reynolds number. Hal ini disebabkan karena semakin besar nilai Reynolds number, aliran fluida memiliki kecenderungan aliran yang bersifat turbulen. Semakin turbulen suatu aliran, semakin baik fluida tersebut melepaskan panas.

\section{KESIMPULAN}

Dari hasil uji eksperimental dan penelitian, dapat disimpulkan bahwa:

1. coolant $A$ memiliki kemampuan untuk memindahkan panas lebih baik daripada coolant $B$ dan air, dimana nilai efektivitas terbesar coolant $A$ sebesar $40 \%$, coolant $B$ memiliki nilai efektivitas terbesarnya $37 \%$, dan air memiliki nilai efektivitas terbesarnya 36,3\%.

2. Semakin besar nilai laju aliran massa fluida, fluida memiliki kecenderungan untuk melepaskan panas yang lebih besar pula.

3. Nilai Reynolds number pada air memiliki nilai yang paling besar jika dibandingkan dengan coolant $A$ dan coolant $B$, hal ini terjadi karena viskositas air memiliki nilai terkecil daripada coolant A dan coolant $B$.

\section{DAFTAR PUSTAKA}

[1] Toyota. (1995). New Step 1 Training Manual, Training Centre, PT Toyota Astra Motor, Jakarta.

[2] Toyota. (1996). Pedoman Reparasi Mesin Seri K, Training Centre, PT Toyota Astra Motor, Jakarta.

[3] Holman, J.P. (2010). Heat Transfer. New York: McGraw-Hill Book Co. ISBN 978-0-07352936-3. 
[4] Made Ricki Murti. (2008). Laju Pembuangan Panas pada Radiator Dengan Fluida Campuran 80\% air dan 20\% RC pada RPM Konstan. Jurnal Ilmiah Teknik Mesin Cakram, Vol. 2, No.1, pp. 4-9.

[5] Dany Pradipta. (2013). Pengaruh Coolant Berbahan Dasar Air Dengan Etilen Glikol Terhadap Unjuk Kerja Perpindahan Panas dan Penurunan Tekanan Radiator Otomotif. Jurnal Ilmiah Teknik Mesin Universitas Sebelas Maret.

[6] Ribut Supriyanto. (2013). Pengaruh Laju Aliran Volumetrik Coolant Terhadap Unjuk Kerja Perpindahan Panas dan Penurunan Tekanan Radiator Otomotif. Jurnal Ilmiah Teknik Mesin Universitas Sebelas Maret.

[7] Frank P. Incropera dan David P. Dewitt. (1996). Fundamentals of Heat and Mass Transfer. Third Edition. New York: John Wiley an Sons. ISBN 0-471-30458-1. 